\title{
Fundamentos metodológicos en la limpieza de estructuras pictóricas: una visión objetiva
}

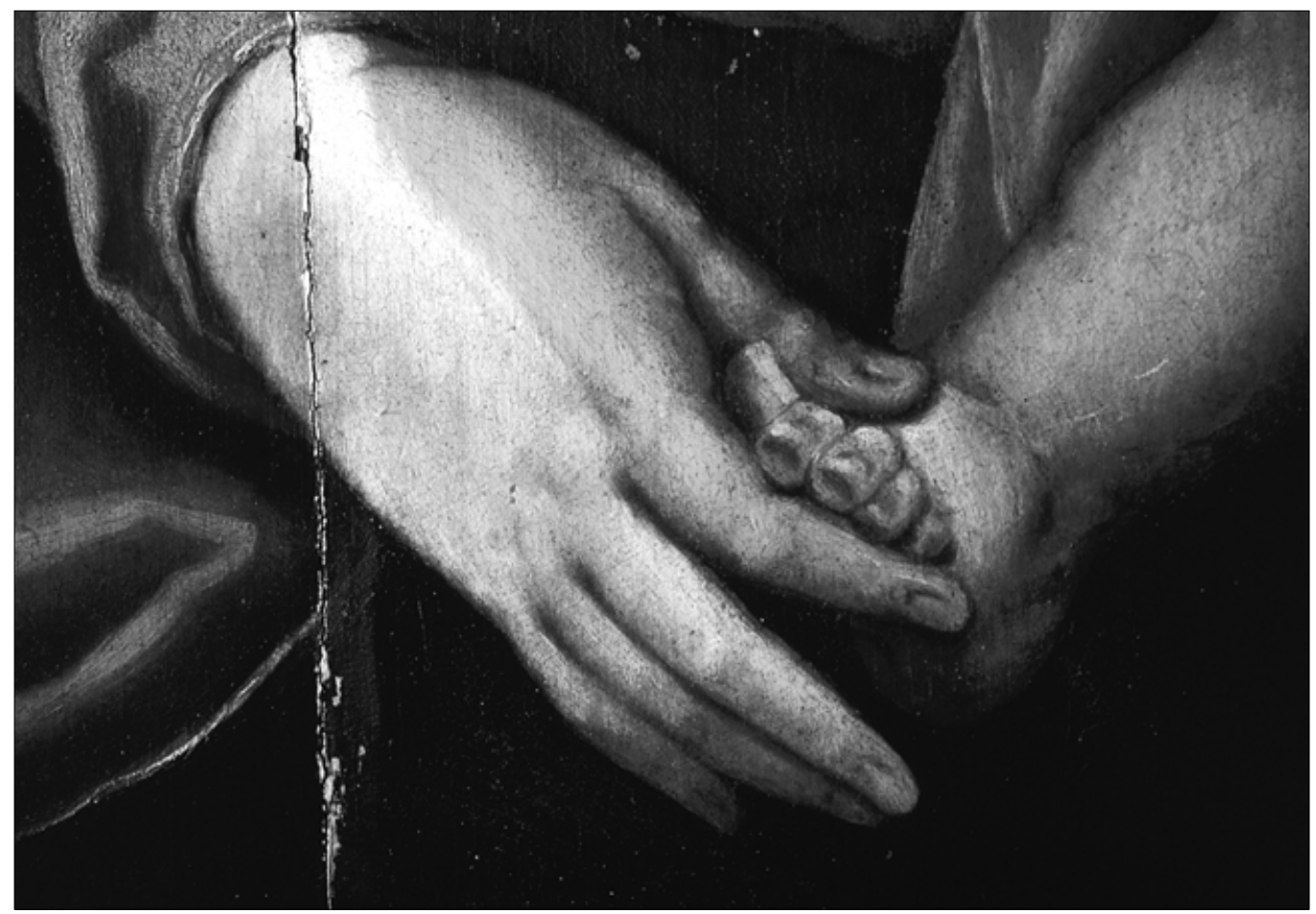

José Manuel Barros García

Dr. en Bellas Artes

El objetivo de este artículo es mostrar la génesis, las bases teóricas y las limitaciones de un planteamiento metodológico en el campo de la limpieza de estructuras pictóricas, al que he denominado como objetivo, en contraposición al crítico (desarrollado este último por autores como Cesare Brandi, Paul Philippot, René Huyghe o Umberto Baldini).

El planteamiento objetivo se expresa a nivel operativo en la llamada limpieza integral o total. Este criterio de limpieza, usual en los países anglosajones, es, en nuestro país, poco conocido en sus fundamentos teóricos, erróneamente interpretado en sus aplicaciones prácticas y evaluado, en muchas ocasiones, de forma mali- ciosa en cuanto a sus limitaciones proyectuales y en cuanto a los resultados operativos. En este estudio se efectúa un análisis crítico, en el que se intentan definir los diferentes aspectos que fundamentan esta metodología, sin eludir las importantes limitaciones que presenta.

En la primera mitad del s. $X X$ se produce en varios países, y en especial en Inglaterra, una fuerte reacción contra el excesivo gusto del pasado siglo hacia las pátinas oscuras. Se trata de mostrar al público los errores cometidos al valorar positivamente las oscuras tonalidades de la pintura antigua y desvelar la existencia de valores cromáticos insospechados, en definitiva, de revelar la auténtica imagen de las obras. Para ello se adopta un sistema de trabajo que también pretende romper con las técnicas de limpieza subjetivas (como por ejemplo la llamada limpieza artístical) y mostrar, de forma racional y científica, una pintura totalmente desprovista de elementos que la desfiguren. 
Se trata de una metodología basada en la objetividad de la intervención, en la búsqueda de una comprensión rigurosa de las técnicas del pasado y en un afán didáctico. La exposición "Cleaned Pictures", inaugurada el 9 de octubre de 1947 en la National Gallery de Londres (un año después de la reapertura del museo tras el dramático paréntesis de la guerra), y el catálogo de la exposición, con prólogo de Philip Hendy, se plantearon como un intento de explicar que la visión que se tenía de las pinturas antiguas estaba condicionada por el oscurecimiento de los barnices y la aplicación intencionada de elementos falseantes como repintes y barnices tintados.

La operación de limpieza pasa así, de ser considerada como un procedimiento cosmético, estético y arbitrario, a ser concebida como una técnica de recuperación, en la que se libera a la pintura original de todos aquellos elementos que la distorsionan, permitiendo su total y correcta apreciación.

\section{Fundamentos teóricos}

No existen muchos textos que nos puedan ayudar a comprender la visión objetiva de la limpieza. Sus defensores, en especial restauradores y químicos, no han sido muy propensos a especular sobre su trabajo, o a aclarar de forma explícita, sus teorías. Posiblemente porque en realidad no ha existido nunca ningún discurso teórico realmente elaborado, sino una serie de nociones que han fundamentado una práctica, ésta sí ilustrada de forma explícita en el importante texto de Ruhemann, The Cleaning of Paintings (Ruhemann, 1982), o en el menos conocido de Bradley, The Treatment of Pictures (Bradley, 1950). Además de estos textos, debe destacarse el catálogo de la exposición de 1947 (Hendy, 1947) y los artículos publicados durante la Cleaning Controversy ${ }^{2}$. Debe mencionarse también otro texto de gran trascendencia como es On humanism, aesthetics and the cleaning of paintings, de Hedley (1985), un valiente y lúcido análisis de los aspectos estéticos que subyacen bajo los criterios de limpieza.

A partir de estos textos, y de otros publicados desde una óptica más crítica, se puede establecer que los fundamentos teóricos en los que se asienta este criterio surgen de la necesidad de comprender, de forma rigurosa y objetiva, cómo están elaboradas las estructuras pictóricas, aclarar la verdadera función de los estratos superficiales y diferenciar conceptos como veladura, barniz, barniz tintado y pátina. En definitiva se trata de señalar sin ningún tipo de ambigüedad los límites entre la estructura pictórica original y los añadidos posteriores.

\section{Barnices pigmentados y pátinas}

Una de las principales aportaciones de la visión objetiva ha sido destruir el mito del aspecto oscuro de las pinturas antiguas, mito influido claramente por la degradación de los barnices y la aplicación de todo tipo de materiales espurios. En los textos publicados durante el s. XIX existía una gran confusión entre los conceptos de veladura, aglutinante y barniz. No siempre se distinguía claramente entre el oscurecimiento del barniz y el del aglutinante. También se confundían, con frecuencia, las veladuras y las capas de barniz.

La moda del ton galerie o jus-musée irrumpió en toda Europa durante el s. XIX. Muchas obras, en numerosos museos, fueron tratadas con barnices oscuros. En la National Gallery de Londres, William Seguier introdujo el uso del Gallery Varnish, una mezcla de aceite y almáciga (también conocido como meguilp), que acentuaba el oscurecimiento de las pinturas. En muchos casos este tono oscuro era intensificado por mezclas con tierra de Cassel, regaliz, café... (Anderson, 1990: 4).

Una cita de la introducción del diario que Eastlake comenzó a escribir en 1855, cuando fue nombrado director del museo londinense, nos aporta interesantes datos acerca de la situación en aquella época:

El barniz que emplearon durante tanto tiempo los Srs. Seguier (William Seguier, conservador, 1824-1843, y John Seguier restaurador 1824(?)-1856), era un barniz de almáciga mezclado a un aceite secante, es decir a un aceite de lino cocido, al cual la incorporación de ciertas sustancias le había conferido propiedades secantes. Describiendo la composición de este barniz, el Sr. J. Seguier habla de una pequeña cantidad de aceite; en realidad hace falta una cantidad bastante grande para obtener, por mezcla con el barniz, el compuesto coagulado al que se denomina meguilp. Cuando utilizan el meguilp, los pintores a menudo mezclan el barniz y el aceite secante a parte iguales; pero una proporción de aceite secante inferior a la mitad es suficiente para producir la coagulación. Con frecuencia los pintores mezclan igualmente esencia de trementina al meguilp: los Srs. Seguier utilizaban el meguilp sin trementina.

Una de las razones por la cual los Srs. Seguier emplearon ese barniz durante tanto tiempo fue probablemente porque los pintores ingleses, a principios de este siglo y tal vez antes, lo utilizaban con frecuencia para sus propios cuadros. Este barniz era conocido en el continente con el nombre de "barniz de los Ingleses", y Mérimée (De la peinture à l'huile, Paris, 1830, página 70) reconoce que es muy adecuado para elaborar veladuras.

Que esta sustancia, empleada como barniz, tenga como efecto aportar a la larga a los cuadros una tinta parda y sombría, y formar manchas desiguales según la cantidad aplicada sobre las diferentes partes de la superficie, es lo que podemos constatar desde hace algunos años en ciertos cuadros de la National Gallery. Cuando el barniz parece haber sido aplicado en una capa uniforme, la tonalidad que da al cuadro no es, en muchos casos, nada desagradable; la aparición de las manchas [...] constituye el principal inconveniente; en uno o dos casos la cantidad de barniz aplicada, tal vez en varias ocasiones, es tal que ensombrece toda la superficie del cuadro (AA.VV., 1950: 250). 
Estas observaciones de Eastlake mostraban que el color oscuro, el tono dorado, de las pinturas no era original, ni producto del envejecimiento natural de los materiales, sino el resultado de sucesivas aplicaciones de barnices, en muchos casos por parte de los propios restauradores.

Sin embargo, muchas de las polémicas contra las limpiezas en los museos, durante el s. XIX, reflejan en buena parte el gusto de un público acostumbrado a disfrutar las pinturas bajo el filtro del golden glow. En los museos de Bruselas también se empleaba una mezcla de aceite, almáciga y pigmentos. La tonalidad resultante era interpretada erróneamente como la pátina del tiempo y se elogiaban sus efectos estéticos (Barros, 1998: 195-196). La supresión de estas capas de barniz causó polémicas apasionadas. Hasta tal punto que en 1930 se envió una petición a un ministro, firmada por cincuenta artistas, declarando que [...] es mejor aún, antes de someter las obras maestras a un tratamiento asesino, dejarlas perecer lentamente de muerte natural y morir en plena belleza (Périer-d'leteren, 1991:4I). El problema era de tal gravedad que Leó Van Puyvelde (Musées Royaux de Beaux-Arts, Bélgica) planteó que era necesaria [...] en ciertos paises, una buena dosis de valor y de honradez profesional para atreverse a mostrar al público un cuadro antiguo en su verdadero estado (Périer-d'leteren, 1991:44).

La limpieza integral se ofrecía como la única forma de mostrar al público el verdadero estado de unas pinturas falseadas por múltiples capas de barnices alterados $y$, en muchas ocasiones, pigmentados. Era necesario hacer comprender a los espectadores que los tonos oscuros o dorados observados en las pinturas no eran más que una pantalla que ocultaba la verdadera obra.

\section{La comprensión de las técnicas del pasado}

Otra de las base teóricas de este planteamiento es considerar que sólo despojando a la pintura de los sedimentos espurios se puede evaluar la exacta naturaleza de una técnica pictórica. De esta forma, el conocimiento real de las pinturas, de las técnicas empleadas, sólo podrá alcanzarse con la eliminación de los materiales no originales. El restaurador Helmut Ruhemann consideraba que la formación de un restaurador sólo podía ser correcta, si ésta se realizaba en contacto directo con una estructura pictórica perfectamente limpia: Sólo el restaurador que ha visto muchas pinturas perfectamente limpias puede educar su sensibilidad en las sutilezas de las obras del maestro. Uno no podrá producir retoques de la alta calidad necesaria a menos que esté mucho tiempo en contacto íntimo con pinturas limpias y puras (Ruhemann, 1982: 217). Ruhemann señaló también la íntima relación existente entre los procesos de limpieza y de estudio de la obra:

Pronto descubrí que la limpieza y el conocimiento son interdependientes. Por un lado, debes conocer la construcción de las diferentes capas de una pintura antes de poder limpiarla de forma segura, mientras que por el otro, es imposible estudiarlas correctamente sin primero extraer los barnices sucios, opacos y oscurecidos, y los repintes que tan a menudo ocultan mucho del original.

"Limpiar para investigar" e "investigar para limpiar" ha tenido por lo menos dos resultados positivos: ha permitido que se pueda disfrutar más de numerosas pinturas y ha permitido que la eliminación del barniz sea más segura de lo que era (Ruhemann, 1982: 25).

La limpieza se plantea así como un proceso de conocimiento de la obra, de revelación de su auténtica realidad a nivel técnico y estético: se convierte en un paso imprescindible para su estudio, comprensión y disfrute. Al mismo tiempo también es fundamental conocer a fondo la obra para asegurar un proceso de limpieza seguro.

En este sentido, una aportación de gran valor ha sido aclarar la confusión existente entre veladuras y barnices. Durante el s. XIX era una creencia común pensar que los pintores empleaban veladuras resinosas aplicadas en ciertas zonas o en toda la superficie de la pintura. Sin embargo, este tipo de recurso técnico no parece haber sido utilizado (por lo menos de forma usual) antes de finales del s. XVIII, y justamente a causa de esta misma confusión sobre las técnicas del pasado. Muchos pintores del s. XIX, basándose en esta idea errónea, aplicaron barnices tintados que actuaban como veladuras generales, aumentando la confusión entre ambos recursos técnicos. Se pensaba que Rembrandt utilizaba resinas blandas en la composición de su aglutinante, por lo que cualquier limpieza con disolventes o reactivos destruía las veladuras finales de sus obras. Las limpiezas y los estudios efectuados en la National Gallery permitieron demostrar lo erróneo de muchas teorías acerca de las técnicas del pasado, en especial acerca del uso generalizado de veladuras resinosas.

Otro argumento que favoreció la necesidad de un planteamiento objetivo y de una práctica de limpieza integral era la necesidad de desenmascarar las falsificaciones, verificar la autenticidad de una pintura y realizar una correcta atribución. De esta forma la limpieza integral se convierte, a la vez, en el instrumento y en el método de redescubrir la verdad oculta, de destruir un estrato de sedimentos que, no sólo enmascara, sino que también falsea y engaña.

\section{Revalorización del color en la pintura antigua}

La revalorización de la importancia del color en la pintura antigua se convierte en otra de las metas del planteamiento objetivo, que tiende a favorecer la recuperación de formas y colores, dando un gran valor a los matices cromáticos. Este planteamiento se apoyará en una serie de estudios sobre la importancia del color en la pintura medieval y renacentista. Por ejemplo, Jonas Gavel recoge toda una serie de testimonios para demostrar que los artistas del Renacimiento no deseaban otra cosa que eliminar el efecto de amarilleamiento del barniz y del propio aceite (Gavel, 1979). 
La intensidad y variedad cromática de la pintura medieval se convierte en un importante punto de referencia. Daniel V. Thompson, en su The Materials and Techniques of Medieval Painting, indica muy claramente la importancia del colorido y la elección de colores intensos en la pintura medieval: En la Edad Media lo correcto era lo correcto; las diferencias estaban claramente marcadas; y los rojos eran rojos y los azules eran azules. Si un pigmento era simplemente deslucido no tenía utilidad para el pintor medieval (Thompson, 1956: 89). Más adelante expresa la incapacidad de los espectadores de disfrutar de la viveza cromática de esta pintura, hecho claramente relacionado con el gusto inglés hacia las pinturas patinadas:

Nosotros no podemos gozar de un festín de color tal como hizo florecer la Edad Media, como tampoco podemos deleitarnos en las colosales delicias de lo que se consideraba una mesa bien puesta. Nuestro gusto en color es como nuestro gusto en comida y bebida, moderado, refinado, civilizado, y, a decir verdad, tal vez un poco triste. No tenemos apetito de excesos fuertes y vigorosos. El espíritu de magnificencia nos abandona cuando miramos las pinturas. Tememos al sol, escogemos la suave sombra, nos gusta nuestro dorado rozado y desgastado y deslustrado, y nuestra plata oxidada; y refugiados bajo el sombrero de nuestra delicada consciencia estética, preferimos no creer en el brillo puro, en la luz de sol llamativa, chillona, en la que se deleitó la Edad Media. Tenemos mayor interés por las armonías sutiles que por la triunfante, maravillosa luminosidad; pero olvidamos que hay armonías del mediodía al igual que hay armonías del alba y del crepúsculo. Comprenderemos mejor la pintura medieval si conseguimos deshacernos de las oscuras gafas del prejuicio, y de las otras oscuras gafas de los efectos superficiales -suciedad y accidente- y vemos las cosas como deberían ser, y no como el tiempo y nuestra propia y delicada digestión las han hecho aparecer (Thompson, 1956: 100).

Thompson indica que la pintura medieval presenta tonalidades frías (grises, azules y violetas) que pueden alterarse gravemente con el envejecimiento de los estratos superficiales. El aspecto oscurecido de estas obras siempre indica la aplicación de materiales posteriores, y no corresponde nunca a la imagen original, de vivo cromatismo.

Todos estos estudios han destruido la idea del efecto oscuro de las pinturas antiguas, demostrando que existía, por parte de los artistas, un interés por el color incluso por encima de otros valores visuales. Estudios posteriores han confirmado esta idea:

La atenta lectura de los contratos españoles correspondientes a los períodos del Renacimiento y del Barroco permite constatar una mayor preocupación por la riqueza y el brillo de la pintura que hacia los puros valores artísticos de la imagen, siendo ésto más claramente apreciable cuanto más bajo era el nivel cultural del ambiente social del cliente y aún del mismo artista. En relación con ello se encuentra la simbología de los valores de los metales preciosos y de los colores que, con su je- rárquica ordenación de los tonos, traducía en un lenguaje directo y expresivo los valores iconográficos y estéticos de la obra (Sánchez y Prieto, 1996: 446).

Se ha demostrado la importancia del refinamiento cromático, de las sutiles variaciones tonales: [...] los contratos indican un refinamiento sobre los azules, una capacidad para discriminar entre unos y otros, con la que nuestra cultura no nos ha provisto (Sánchez y Prieto, 1996: 445).

Los responsables de la N. Gallery aportaron pruebas sobre la importancia que daban los pintores al hecho de que sus obras se mantuvieran con colores brillantes y sobre el rechazo generalizado hacia el oscurecimiento provocado por la alteración de los barnices. Se defendió también la idea de que los barnices antiguos tendían a ser trasparentes y que no alteraban el cromatismo pictórico. La defensa de la importancia del color se apoyó también en el estudio de la pintura impresionista y contemporánea. El vocabulario de la pintura impresionista depende de contrastes de colores vívidos y sutiles interacciones cromáticas. Esto hace que cualquier alteración del barniz, aún la más leve, distorsione gravemente la visión de la obra. Se hicieron frecuentes comparaciones entre pintores antiguos y pintores impresionistas. Ruhemann (1982: 88) indica, por ejemplo, que la Venus del espejo de Velázquez es mucho más luminosa que la Eva Gonzálès de Manet. Este tipo de comparaciones tenía como objetivo resaltar la importancia de la luz y del color en la pintura antigua, valorar su modernidad y, en algunos casos, explicar ciertas disonancias cromáticas:

Cuando en 1962 el verdadero brillo de ciertos azules en dos o tres pinturas de Tiziano fue revelado por la limpieza, ello supuso una cierta decepción para un número de amantes del arte. Estamos de acuerdo con los críticos en que esos azules sin su velo de barniz sucio, aparecen ahora un poco fuera de lugar, tal vez en parte porque algunos verdes se han vuelto pardos con el tiempo; sin embargo, consideramos que esas distancias azules quizás hayan sido siempre demasiado estridentes para el gusto de algunas personas. Lo azulado de las distancias fue un gran descubrimiento en el Renacimiento y los pintores bien pueden haberlo exagerado, como los impresionistas exageraron las sombras azules que descubrieron, para gran enojo de sus contemporáneos. En cada gran museo pictórico uno puede hallar muchas pinturas de maestros renacentistas, románticos e impresionistas, con distancias que no parecen menos "fuera de lugar" que las de los criticados Tiziano [...] (Ruhemann, 1982: 238).

El estudio de las pinturas impresionistas sirvió también para plantear la cuestión del barnizado de las pinturas $y$, en especial, el hecho de que muchos pintores de este periodo no deseaban que sus pinturas fuesen barnizadas (Bomford et al., 1990: I0I). Esto se empleó para reforzar la argumentación de la $\mathrm{N}$. Gallery acerca del gran interés de los pintores, antiguos y contemporáneos, por mantener un cromatismo fresco e intenso en sus obras. 


\section{La función del barniz}

Una de las cuestiones que más se debatieron durante la Cleaning Controversy fue la función del barniz en la obra pictórica. Los defensores de la visión objetiva plantearon que un barniz sólo posee una función protectora, sin ninguna importancia en la definición de la imagen. Se señaló siempre la trasparencia del barniz y su función protectora, sin entrar nunca en la cuestión de su posible función estética. También se afirmó, de forma contundente, que los pintores nunca utilizaron capas de barniz para obtener determinados efectos en la elaboración expresiva de la obra (Plesters, 1988: 176-178). Witherop (1962) y Plesters (1988: 165166 y 175-176) defendieron la idea de que, aunque los barnices antiguos pudiesen presentar una cierta coloración al ser preparados (en especial los barnices grasos), se aplicaban en capas extremadamente finas para obtener un efecto de trasparencia.

En todos los casos se estableció una separación clara entre la estructura pictórica y la capa de barniz. Este estrato superficial se contemplaba siempre desde un doble punto de vista, que reforzaba la idea de elemento accesorio al estrato pictórico: (a) negativamente, como una fuente de potenciales daños para la pintura o de molestias en la restauración y, (b) positivamente, como un estrato protector que podía ser renovado cuando fuese necesario.

Resulta muy significativo que Bradley, al señalar los cuatro objetivos de una limpieza señale, en primer lugar, la prevención de daños en la pintura a causa de la contracción del barniz: El propósito más importante de la limpieza es prevenir tales daños, no mejorar la apariencia de la pintura (Bradley, 1950: 2.01). Las siguientes causas que pueden hacer necesaria una limpieza son: facilitar un tratamiento estructural, como la fijación de la película pictórica, y la sustitución de un estrato deteriorado por otro que cumpla mejor su función protectora. El planteamiento de Bradley resulta muy significativo, a pesar de su aparente sentido común, dado que no suele ser tan frecuente que el barniz produzca daños directos en la pintura o dificulte significativamente otros procesos de restauración. Bradley intenta situar el barniz en una dimensión ajena a la estructura pictórica y a los problemas estéticos. Se plantea el desbarnizado casi como un proceso obligatorio de conservación preventiva, de eliminación higiénica de una capa extraña a la realidad objetiva de la obra.

Dado que la capa de barniz se sitúa en una dimensión diferente a la de la capa pictórica, se rechaza cualquier utilización de un estrato de barniz con una función compensatoria de desequilibrios en la pintura. No se admite, por ejemplo, que el barniz pueda dejarse, de forma parcial, en algunas zonas, para compensar fuertes alteraciones cromáticas o desequilibrios causados por anteriores limpiezas. Tras la limpieza integral, disonancias como alteraciones cromáticas o arrepentimientos podrán disimularse en la fase de reintegración. Sólo después de una completa limpieza se podrá estudiar adecuadamente la obra y evaluar de forma más objetiva la necesidad de estos ajustes pictóricos (Ruhemann, 1982: 231; Hedley, 1985: 7-10).

\section{La limpieza integral}

El planteamiento de la limpieza integral puede explicarse de forma muy simple: los barnices oscurecidos, los repintes y cualquier tipo de material acumulado, no original, deben ser eliminados, en su totalidad, de la obra. Este tipo de enfoque es el más común en Inglaterra y en los Estados Unidos.

\section{La National Gallery y Helmut Ruhemann}

Suele señalarse que la National Gallery de Londres es la institución que representa de forma más evidente el planteamiento a ultranza de la limpieza integral. El restaurador Helmut Ruhemann ha sido uno de los defensores más enérgicos de esta postura ante el problema de la limpieza.

Ruhemann, con una sólida formación pictórica y en la práctica de la restauración a nivel privado, fue nombrado restaurador en el Kaiser Friedrich Museum, donde trabajó durante cuatro años. En 1934 se trasladó a Londres, requerido por Sir Kenneth Clark. A partir de entonces comienza su etapa más importante, como restaurador en la National Gallery (Ruhemann, 1982: 31-45). Durante la Segunda Guerra Mundial, las pinturas del museo londinense fueron trasladadas a casas de campo. Durante esta época, Ruhemann prosiguió con su trabajo de limpieza de muchas de las obras más emblemáticas del museo.

En 1946 fue nombrado Consultant Restorer en la National Gallery, trabajando también para el Courtauld Institute of Art. Su dedicación profesional a la restauración se combinó con la formación de jóvenes restauradores. También debe destacarse su labor como divulgador de las técnicas de restauración y defensor del empleo de las técnicas científicas. Fue también uno de los miembros fundadores del International Institute for Conservation (I.I.C.).

Ruhemann puso en un primer término la necesidad de recuperar las obras tal como deben ser vistas, para poder estudiarlas de forma objetiva, sin el impedimento de repintes o barnices oscurecidos. De esta forma los restauradores deben realizar su trabajo [...] para preservar y mostrar en su mejor aspecto cada partícula que queda de una pintura (Ruhemann, 1963: 202). El restaurador tiene la obligación de poner al descubierto cada partícula de la pintura original, de recuperar cada línea del dibujo, cada matiz cromático, sin las alteraciones provocadas por los sedimentos depositados en épocas posteriores al momento de su ejecución.

Helmut Ruhemann se planteó la obligación, frente a la propia obra y al espectador, de establecer un criterio de trabajo en el que la franqueza y la objetividad serían las características más esenciales. La obligación pe- 
dagógica de un museo, con respecto a los espectadores, restauradores, historiadores o copistas haría necesaria la labor de limpieza y de presentar las obras de forma que no pudiesen producirse confusiones en la apreciación de la estructura original. En un cuestionario del ICOM, publicado en 1950, los responsables de la National Gallery se expresaban así sobre el concepto de limpieza:

El deber de un museo público es presentar los cuadros (documentos únicos del genio y de la técnica de su creador) tan exentos como sea posible de alteraciones. No existirá más que una sola regla: presentar la obra con un aspecto lo más próximo posible al que tenía originalmente. La suciedad, el barniz oscurecido o que se ha vuelto parcialmente opaco, los barnices tintados aplicados a destiempo, los retoques que no son afines ya al original, los repintes que lo recubren, los añadidos a la composición, tales son los diferentes factores que alteran el carácter original de la obra. Una limpieza parcial no constituye más que una nueva falsificación. De hecho un cuadro sucio y decolorado normalmente revela a un ojo ejercitado la intención del autor; un cuadro que ha sido sometido a una limpieza parcial lo hace raramente.

Las modificaciones que los valores y colores originales han sufrido a causa del envejecimiento raramente pueden ser apreciadas si las aportaciones posteriores no han sido eliminadas. Aún entonces no podemos más que formular hipótesis en cuanto a la extensión de esas modificaciones. Las deformaciones debidas al oscurecimiento del barniz son seguras (AA.VV., 1950: 250).

Tal como señala este manifiesto, la objetividad de una limpieza sólo puede obtenerse mediante una extracción completa, integral, de cualquier tipo de suciedad, barniz o repinte presente en la obra. Cualquier criterio que defienda la permanencia de aditamentos posteriores, no originales, es rechazado de forma contundente.

\section{Una limpieza objetiva}

El criterio objetivo se plantea como principal meta recuperar el estado original de la obra, su verdad. Este estado original viene determinado exclusivamente por la capa de pintura, desprovista de barnices oscurecidos, suciedad, repintes o cualquier otro sedimento histórico no aplicado por la mano del propio pintor. Este planteamiento implica que la pintura totalmente limpia corresponde exactamente a la intención original, a la realidad auténtica de la obra de arte.

Desde este punto de vista las técnicas de limpieza parcial o selectiva (en las que no se eliminan de forma completa los sedimentos históricos), sea cual sea su justificación, son contempladas de forma muy negativa, al ser consideradas como un tipo de intervención subjetiva, arbitraria, y que puede producir un mayor grado de adulteración de la obra. Se considera como una prueba de honradez intelectual, mostrar una realidad que ofrezca un instrumento de trabajo fiable a todo estudio histórico y elimine los errores de interpretación (Guillaume-Chavannes, 1987: II2). Bradley plantea de este modo la limpieza:

Cada pintura debería ser limpiada completamente; esto es, todas las capas superficiales, repintes, y excrecencias deberían ser eliminadas, porque incluso una fina capa podría causar daños, reducir la efectividad del tratamiento estructural, distorsionar la composición, o deteriorarse y decolorarse aún más. La limpieza parcial sólo está justificada si la limpieza completa no es segura, si el coste de la limpieza completa no está justificado por la importancia o el valor de la pintura, o si es más urgente el tratamiento de otros objetos de la colección (Bradley, 1950: 2.02).

Bradley señala, como es habitual en los defensores del planteamiento objetivo, la obligación de la limpieza integral. Este criterio es considerado como un imperativo metodológico, no como una opción entre otras. Una limpieza que no sea planteada, de forma objetiva, como una limpieza total, sólo es aceptada, como mal menor, para ciertos casos. Una intervención parcial nunca se considera admisible para una pintura de gran valor estético, que no plantee ningún imposibilidad técnica para recuperar al máximo los valores cromáticos.

El rigor objetivo con el que se aborda el problema de la limpieza supone también conceder una gran importancia a las técnicas científicas. Las operaciones relacionadas con la conservación de las obras de arte son consideradas así en su relación con la química y la física. Se trata de intervenciones que se realizarán bajo la responsabilidad de profesionales, que deben actuar guiados por estrictas normas, asentadas en una sólida base científica. La limpieza ya no es vista como una operación subjetiva, donde el restaurador puede eliminar de forma arbitraria aquellos estratos que su experiencia le señala como espurios, sin justificación de ningún tipo.

Desde finales del s. XIX se plantea la cuestión de que el análisis científico permitirá identificar los materiales originales y diferenciarlos de los añadidos posteriormente, colaborando al establecimiento de unos criterios objetivos en las operaciones de limpieza. En un ambiente de optimismo tecnológico, la estructura pictórica empezará a ser vista como una construcción que puede comprenderse, en todos sus aspectos y potencialidades, gracias al uso de las técnicas científicas de examen y análisis. Éstas ofrecerán la llave que permitirá desvelar todos los secretos que ocultan las técnicas antiguas.

Los responsables de la National Gallery se interesaron muy pronto por las técnicas de examen a su disposición, en especial los rayos $X$ y la lámpara de ultravioleta, y también otras menos usuales en aquel momento como las técnicas de colorimetría (Ruhemann, 1982: 119 y ss.). Estas técnicas se utilizaron para estudiar el estado de las obras antes de la intervención, documentar el propio proceso de limpieza y verificar el resultado tras la restauración. 
La documentación aportada por los responsables del museo durante la Cleaning Controversy incluía fotografías realizadas con iluminación convencional, luz ultravioleta, infrarrojos y radiografías. Se documentó tanto el estado inicial como el final. Se realizó también una documentación de la propia intervención, en la que se incluían radiografías que mostraban fases del propio proceso de limpieza (Weaver, Stout y Coremans, 1950: I 16-124). También se efectuaron macrofotografías de zonas especialmente significativas, antes y después de la intervención.

El análisis de los hisopos se utilizó para verificar la posible extracción de pigmentos originales en las limpiezas de dos de las pinturas estudiadas por la comisión Weaver ${ }^{3}$. Una vez extraído el residuo, se realizó un estudio microscópico, microquímico y espectrográfico. Por ejemplo, en una de las muestras extraídas de la Mujer en el baño de Rembrandt se comprobó la presencia de zinc, lo que indicaba que la capa eliminada era un repinte (Weaver, Stout y Coremans, 1950: |43-144).

A pesar de ciertas limitaciones, era muy evidente la voluntad metodológica de realizar una documentación científica, de un proceso que no solía documentarse de forma tan exhaustiva y rigurosa. El proceso de examen y análisis de la obra permitía comprobar la necesidad de la intervención, verificar la corrección del proceso de limpieza durante la propia intervención y evaluar el resultado final y la presencia de posibles daños. Estas técnicas permitían reforzar la objetividad del proceso, fundamentar cualquier decisión que se tomase (como por ejemplo la eliminación de repintes) y documentar el proceso de limpieza con gran rigor.

\section{Los límites de la limpieza integral}

Las bases sobre las que se apoya el criterio objetivo suponen una recuperación de la obra alejada de planteamientos subjetivos y arbitrarios y el deseo de un conocimiento científico de las estructuras pictóricas.

Estas nociones han permitido que la restauración madure como una disciplina técnica rigurosa, al servicio de la conservación y comprensión de las obras de arte. Sin embargo, la tendencia marcada por unos criterios en los que el deseo de limpieza integral se convierte en una norma obligatoria, ha puesto en evidencia ciertas limitaciones y problemas.

\section{La confianza en los procedimientos utilizados}

Uno de los problemas más importantes que plantea este criterio, en sus posiciones más extremas, es la excesiva confianza puesta en los sistemas de trabajo utilizados. Se soslayan ciertas cuestiones de gran importancia, como los posibles daños que pueden producirse en la pintura como consecuencia de una limpieza y se tiende a adoptar la creencia en la solidez a toda prueba de la película de óleo antigua. En los años 50 los responsables de la National Gallery defendían la idea de que los pintores emplearon, por lo menos hasta el s. XVIII, una técnica pictórica que permitía realizar limpiezas con disolventes sin excesivos problemas. Se consideraba que las veladuras, siempre realizadas exclusivamente con un aceite secante, podían resistir perfectamente un desbarnizado integral correctamente realizado (Weaver, Stout y Coremans, 1950: 159-160).

Las opiniones de Ruhemann acerca de los trabajos de Stolow sobre la lixiviación son muy representativas de este tipo de postura. A partir de 1954 Nathan Stolow inició una importante investigación sobre la acción de disolventes sobre películas de aceite secante, pigmentadas y no pigmentadas, en el Courtauld Institute of Art y en el laboratorio de la National Gallery of Canada. Stolow realizó un estudio que demostraba la pérdida, en el aglutinante oleoso de una pintura, de moléculas de bajo peso molecular durante el proceso de limpieza con disolventes orgánicos. De esta forma pudo comprobar, por ejemplo, que la acetona producía una intensa lixiviación en la pintura (Stolow, 1985).

Aunque Ruhemann admitió la importancia de esta investigación, negó de forma rotunda la validez de los resultados obtenidos por Stolow, al considerar que las pruebas realizadas no se correspondían en ningún caso con un proceso normal de limpieza en una pintura. Ruhemann se apoyó en su propia experiencia y habilidad como restaurador para desacreditar los resultados de estos estudios, y ofreció, como solución para limpiezas difíciles, en especial para pinturas con aglutinantes óleo-resinosos, la acetona. Ruhemann (1982: 197-198 y 201) hizo una defensa apasionada de este disolvente por su rápida evaporación, considerando que las limpiezas integrales realizadas con acetona y guiadas por la pericia del restaurador eran perfectamente seguras e inocuas.

Ruhemann, como otros restauradores, tenía sus preferencias en cuanto a los materiales que debían emplearse en una restauración. En cuanto al proceso de limpieza, defiende el uso de la acetona criticando el empleo del alcohol etílico, al que considera mucho menos seguro para el proceso de limpieza, por su evaporación más lenta. No aporta más pruebas que su propia experiencia profesional y su, a veces desmesurada, confianza en el propio sistema de trabajo.

Ruhemann sólo acepta las conclusiones de los estudios científicos cuando éstos avalan la inocuidad de los procedimientos de limpieza utilizados. Es muy característico de su punto de vista y del de otros partidarios del planteamiento objetivo, admitir la existencia de algunos riesgos en una limpieza pero considerar que todos son subsanables gracias a la pericia del restaurador. En general, los únicos riesgos que realmente se admiten son los derivados de la incompetencia del operador, nunca de la propia complejidad del proceso, ni de las limitaciones de las técnicas empleadas, ni de lo incompleto de los conocimientos. 


\section{La recuperación del estado original}

H. Ruhemann y otros responsables de la National Gallery defendieron, como uno de los criterios más importantes, el principio de la recuperación de la intención original. Se trataba de presentar de forma objetiva, sin distorsiones en la interpretación, las intenciones del artista. Mac Laren y Werner plantearon cual debía ser el objetivo de la restauración de la siguiente forma: Es de suponer que está más allá de cualquier discusión que el propósito de los responsables del cuidado de las pinturas es presentarlas tan cercanas como sea posible al estado en el que el artista deseaba que fuesen vistas (MacLaren y Werner, 1950: 189). En su forma más dogmática, este planteamiento presupone que el restaurador es guiado por la intención del maestro, eliminando todos los elementos no originales y recuperando una estructura pictórica que mostrará esta intención original de forma objetiva.

Se han planteado numerosas críticas a este planteamiento positivista. La principal es que los materiales empleados por el artista pierden con el tiempo, y de forma inevitable, fidelidad en su relación con las intenciones originales. Desde ese punto de vista, de transformación continua de la obra, el estado original sólo puede plantearse como una hipótesis de trabajo, no como una realidad que pueda recuperarse físicamente (Marijnissen, 1967: 221-229).

En 1946, Wimsatt y Beardsley publicaron un importante artículo que planteó lo que se conoce como la falacia intencional. Este concepto se aplica cuando los críticos, historiadores o restauradores asocian sus análisis e interpretaciones con el propio trabajo del artista. La falacia intencional es un concepto que plantea que las interpretaciones pertenecen al observador y no pueden identificarse con el propio trabajo del autor. El observador es quien realmente supone cual es esa intención, y por lo tanto no puede valorarla como si tratase de una información objetiva, ajena a él e identificable con la propia obra (Dykstra, 1996). Incluso se ha llegado a plantear que la obra, una vez realizada, trasciende sus circunstancias originales. Se produce un fenómeno de distanciamiento, en el que lo creado se convierte en algo, hasta cierto punto, autónomo de su autor.

En general, el principio de seguir la intención del artista no ha sobrevivido como un criterio en el campo de la restauración. La intención del autor es algo muy difícil de evaluar. Sólo en contadas ocasiones se dispone de una información fiable sobre sus deseos en cuanto a la presentación de las pinturas.

\section{La presentación de la obra}

La limpieza integral se plantea como una operación totalmente (e higiénicamente) homogénea, con una marcada intención de claridad y objetividad. Esta solución única es justamente uno de los problemas más graves que plantea este criterio de trabajo, ya que todas las obras son tratadas de la misma forma. En todas las intervenciones se fijan los mismos objetivos (Hedley, 1985: 6).

Uno de los argumentos más utilizados por los defensores de la limpieza total ha sido la recuperación de la pintura antigua a un nivel cromático semejante al de una pintura impresionista. Si en este planteamiento hay una sana intención de rebelarse contra el fanático gusto hacia las pátinas oscuras, también plantea una peligrosa tendencia hacia una limpieza excesiva para conseguir estos efectos cromáticos a cualquier precio. Así lo señalaba Longhi en 1951:

Cuántas veces, tras la enérgica limpieza de una tabla primitiva he oído susurrar [...]:" ¡Pero qué modernos eran estos antiguos! ¿No parece Matisse?" O, tras el drástico lavado de un Tiziano: "ipero mira cómo parece Manet, cómo parece Gauguin!" [...] Son ecuaciones sumamente peligrosas porque incitan a convertir las pinturas antiguas en brillantes y multicolores huevos de Pascua, tal vez para arrastrarlas sobre el plano racional del mobiliario moderno, entre las sillas de Aalto, y cosas similares. Se puede estar seguro que en muchos de estos casos, los pobres primitivos habrán sido, no ya "limpiados", sino como mínimo "relimpiados" (Longhi, 195I).

Se ha tendido a pensar que las pinturas al temple medievales no habían sido originalmente barnizadas ${ }^{4}$, que el acabado cromático debía ser semejante al de las miniaturas. Durante la limpieza del Pentecostés, perteneciente al retablo de San Pier Maggiore, atribuido a Jacopo di Cione (National Gallery, Londres), aparecieron pequeños restos de un barniz óleo-resinoso a base de aceite de linaza, una resina del tipo sandáraca y minio de plomo como secativo (Dunkerton, Kirby y White, 1990). Esto ha demostrado el uso en Italia, durante los ss. XIV-XV, de barnices oleosos, lo que ha obligado a los restauradores de la National Gallery a reconsiderar el acabado de las pinturas al temple italianas:

Tal vez deberíamos reconsiderar nuestra visión de la apariencia original de la superficie de las pinturas italianas al temple realizadas en fecha temprana. Aplicado recientemente, un barniz oleorresinoso sería perfectamente claro, pero con un acabado lustroso que es ajeno a la idea corriente entre la mayoría de los restauradores sobre cuál era el aspecto de estas pinturas perseguido inicialmente (Bomford et al., 1995: 185).

El incremento en la saturación del color y el brillo obtenido por el barnizado podría haber sido el contrapunto necesario para el lustre del oro bruñido (Dunkerton, Kirby y White, 1990: 68). Sin embargo, y a pesar de un cierto cambio en los planteamientos de limpieza en el museo londinense en los últimos años, con un cierto alejamiento del dogmatismo de la década de los 50, el criterio objetivo seguido por los responsables de la N. Gallery ha excluido cualquier discusión sobre cuestiones estéticas, como el tipo de presentación más adecuada a una pintura. En los planteamientos iniciales de la limpieza integral (tal como es formulada por autores como Helmut 
Ruhemann) no existe ningún interés hacia ningún otro aspecto de la presentación de la obra que no sea la recuperación del cromatismo original. No se plantea la posibilidad de descubrir la presencia de barnices originales, sea porque se considera que las pinturas nunca fueron barnizadas (como en el caso de la pintura medieval) o porque se presume que las pinturas no han podido llegar hasta la actualidad con barnices originales (Ruhemann, 1982: 215; Plesters, 1988: 179 y 183). Todo barniz oscurecido es considerado siempre como un añadido posterior que desvirtúa el carácter de la obra.

La insistencia en explicar las prácticas de épocas anteriores en aplicar barnices tintados posee, en un primer momento, el propósito didáctico de revelar que las pinturas no fueron concebidas originalmente tan oscuras. Sin embargo, este planteamiento previo parece haber pasado a ser una forma de justificar todas las limpiezas totales: puesto que ya no quedan barnices originales y todos los que nos podamos encontrar son espurios, se puede proceder con absoluta tranquilidad a su eliminación integral.

En ningún momento se acepta que los sedimentos depositados en la superficie puedan poseer alguna función en la presentación de la obra. Cualquier cuestión, como las referentes a factores históricos o estéticos, que no pueda ser corroborada por las técnicas científicas, es considerada como inútil, no merece consideración por ser de carácter personal, arbitrario. En los casos más extremos, se considera subjetiva cualquier aportación de datos por parte de los historiadores y cualquier constatación ligada a la experiencia visual, y objetiva cualquier deducción e interpretación que tenga su origen en un dato químico o físico. Tal como señala Marijnissen (1967: 344), por desgracia el fenómeno de la belleza no puede ser medido ni representado en forma de ecuación. Una apreciación de este fenómeno será, en su mayor parte, cualitativa y no cuantitativa como la de los fenómenos físicos. Rees Jones (1988: 152) también ha señalado que esta postura está planteada con una mentalidad restrictiva y materialista que no tiene en cuenta los fenómenos relacionados con la observación, en especial, los aspectos estéticos.

Por paradójico que pueda parecer, Ruhemann narra un caso donde se demuestra el valor e importancia que pueden tener los sedimentos depositados sobre la pintura:

En 1956 fui a Guatemala en nombre de la UNESCO durante tres meses, para formar tres artistas-artesanos en restauración de pinturas. Las numerosas pinturas religiosas de las encantadoras iglesias barrocas necesitaban urgente atención, aunque pocas eran de gran valor. Prácticamente ninguna había sido restaurada o limpiada, pero cuando llegó el momento de eliminar los barnices oscurecidos de algunas de las pinturas sagradas yo vacilé. Se me ocurrió que los habitantes, la gran mayoría de los cuales son Indios, de hecho descendientes de los Maya, podrían estar horrorizados si de repente viesen sus Santos, a quienes siempre habían conocido con una piel tan morena como la suya propia, surgir como blancos europeos (Ruhemann, 1982: 46 y 49).

Ruhemann muestra aquí cómo una alteración en los sedimentos no originales puede tener un valor en la forma de entender la obra. Sin embargo, este ejemplo no contradice, aunque pueda parecer lo contrario, sus ideas acerca de una limpieza completa. Ruhemann indica que se trata de pinturas de escaso valor y de uso religioso. No se trata pues de Obras Maestras, ni nos encontramos en el espacio de un museo destinado al deber de revelar el mensaje del Autor a un público culto, sino en una iglesia barroca de Guatemala donde el pueblo se dirige a adorar a sus Santos. Porque debe indicarse que el discurso general del criterio objetivo tiende a estar impregnado de, lo que podría denominarse, un cierto regusto aristocrático: siempre se da una mayor importancia a las obras de los grandes autores del pasado (great masterpiece), sobre las cuales pesa la obligación de una recuperación completa. Sólo se acepta que pinturas menos agraciadas, de menor valor, puedan seguir existiendo bajo el velo dorado de los barnices.

Notas

I. Este método de trabajo consistía en limpiar la pintura de forma desigual según una interpretación subjetiva del restaurador. De esta forma se podía conseguir hacer algo más atrayentes pinturas mediocres, al obtener efectos pictóricos de mayor contraste, y se evitaban los problemas relacionados con las zonas más sensibles a los disolventes.

2. Polémica centrada en las limpiezas realizadas en la National Gallery de Londres. Se inició tras la reapertura del museo, al finalizar la Segunda Guerra Mundial, desarrollándose durante la década de los 50. A principios de los años 60 se prolongó en una segunda fase. Esta polémica sirvió para mostrar la división existente entre dos posturas radicales acerca de los objetivos y procedimientos en la limpieza de pinturas: la postura objetiva y la crítica Sobre la Cleaning Controversy existe una amplia bibliografía. Véanse, en especial, Ruhemann, 1982, Wechsler, 1987 y Conti, 1988.
3. Las numerosas críticas a las intervenciones realizadas en la National Gallery provocaron la creación de una comisión investigadora para examinar los procedimientos de limpieza empleados en el museo. La comisión estaba formada por el Dr. Paul Coremans (Laboratorio Central, Museos Nacionales Belgas), el Dr. G. L. Stout (Departamento de Conservación, Fogg Museum of Art, Harvard University) y el Dr. J. R. H. Weaver (Presidente del Trinity College, Oxford). En mayo de 1948 se publicó un resumen del Weaver Report en el Times, apoyando los criterios de la National Gallery. En 1950 el informe se publicó parcialmente en la revista Museum (Weaver, Stout y Coremans, 1950).

4. Como respuesta a una de las preguntas incluidas en un cuestionario del ICOM, enviado en 1948 a numerosos museos, los responsables de la National Gallery de Londres afirmaban que el barnizado no era una práctica corriente en los ss. XIV-XV (AA.W., 1950: 249). 
AA.VV. (1950): "Le dévernissage des tableaux a la National Gallery". Museum, vol. III n³, pp. 247-25I.

ANDERSON, Jaynie (1990): "The first cleaning controversy at the National Gallery 1846-1853". Appearance, opinion, change: evaluating the look of paintings, papers given at a conference held jointly by the United Kingdom Institute for Conservation and the Asociation of Art Historians, pp. 3-7.

BARROS, J. M. (1998): "La imagen transfigurada". Espills de Justícia, catálogo de la exposición, 2 oct.-15 nov., 1998, Universitat de València, pp. 193-218.

BOMFORD, D. et al. (1990): Art in the Making: Impressionism. London. National Gallery.

BOMFORD, D. et al. (1995): Art in the Making. Italian Painting Before 1400. London. National Gallery Publications Ltd., 1989. Edición española: La pintura italiana hasta 1400. Barcelona. Ediciones del Serbal.

BRADLEY Jr., Morton C. (1950): The Treatment of Pictures. Cambridge, Mass

CONTI, A.(1988): Sul Restauro. Torino. Piccola Biblioteca Einaudi.

DUNKERTON, J.; KIRBY, J. y WHITE, R. ( 1990): "Varnish and early italian tempera paintings". Cleaning, Retouching and Coatings, Preprints of the Contributions to the Brussels Congress, 3-7 september 1990, London. IIC, pp. 63-69.

DYKSTRA, Steven W. (1996): "The artist's intention and the intentional fallacy in fine arts conservation". Journal of the American Institute for Conservation, 35 n³, pp. 197-218.

GAVEL, J. (1979): Colour. A Study of its Position in the Art Theory of the Quattro \& Cinquecento. Stockholm.

GUILLAUME-CHAVANNES, G. (1987): "La conservation des peintures au Courtauld Institute et a la Tate Gallery". Conservation Restauration des Biens Culturels, Paris 15-16 octobre 1987. Paris. ARAAFU, pp. I 10- I I5.

HEDLEY, G. (1985): On humanism, aesthetics and the cleaning of paintings. Lecture presented February 26 and March 5, 1985 at the Canadian Conservation Institute.

HENDY, Sir Philip (1947): An Exhibition of Cleaned Pictures. London. National Gallery.

LONGHI, R. (|95|): "Dei restauri". Paragone, 23, pp. 3-7.

MacLAREN, Neil y WERNER, Anthony (1950): "Some factual observations on varnishes and glazes". The Burlington Magazine, XCll, pp. 189-192.
MARIJNISSEN, R. H. (1967): Degradation, conservation et restauration de l'oeuvre d'art. Bruxelles. Arcade. 2 vol .

PÉRIER-D'IETEREN, C. (199I): La Restauration en Belgique de 1830 à nos jours. Peinture, Sculpture, Architecture. Liège. Piere Mardaga.

PLESTERS, Joyce (1988): "Dark varnishes-some further comments". The Burlington Magazine, CIV, 1962, pp. 452-460. Publicado con el título "Vernici scure. Ulteriori osservazioni" en Conti: |61-190.

REES JONES, S. ( 1988): "Science and the art of picture cleaning". Burlington Magazine, CIV, 1962, pp. 60-62. Publicado con el título "La scienza e l'arte di pulire i dipinti” en Conti: 15 I- 159.

RUHEMANN, H. (1963): "The training of restorers". Recent Advances in Conservation. London. Butterworths, pp. 202-205.

RUHEMANN, H. (1982): The Cleaning of Paintings. New York. Hacker Art Books. (। ${ }^{\mathrm{a}}$ ed. 1968)

SÁNCHEZ, A. y PRIETO, M. (1996): "El color en los contratos: aportaciones para el estudio de la pintura sobre tabla en España (siglos XIV-XVII)". Actas del XI Congreso de Conservación y Restauración de Bienes Culturales. Castellón. vol. II, pp. 439-45I.

STOLOW, N. (1985): "Solvent action: some fundamental researches into the picture-cleaning problem". En FELLER, R.L.; STOLOW, N. y JONES, E. H.: On picture varnishes and their solvents, publicación original: Oberlin, Ohio. Intermuseum Conservation Association, 1959. Edición revisada: Cleveland, Ohio. The Press of Case Western Reserve University, 197I. Reedición: Washington. National Gallery of Art, pp. 45- I I6.

THOMPSON, D. V. (1956): The materials of medieval painting. New York. Dover Publications.

WEAVER, J.R.H.; STOUT, George L. y COREMANS, Paul ( 1950): Report of a Committee of Confidential Inquiry into the Cleaning and the Care of Pictures in the National Gallery, Mimeogr., iii + 54 pp., London, 1947. Publicado parcialmente en una traducción al francés con el título "Le Rapport Weaver sur le nettoyage des peintures à la National Gallery à Londres". Museum, vol. III n² 2, pp. |36-176.

WECHSLER, Bettina (1987): "Cleaning Controversy: Zur Diskussion der Gemäldereinigung in England von 1946-1963". Zeitschrift für Kunsttechnologie und Konservierung, I heft 2, pp. 88-132.

WIMSATT, W.K. y BEARDSLEY, M. (1946): "The intentional fa"lacy". Sewanee Review, 54, pp. 468-488.

WITHEROP, J. Coburn (1962): "Letter concerning the National Gallery (London) Cleaning Controversy". The Burlington Magazine, CIV, pp. 265-266. 